\title{
Snow isotopic content change by sublimation
}

\author{
Sergey A. SOKRATOV, Vladimir N. GOLUBEV \\ Laboratory of Snow Avalanches and Debris Flows, Faculty of Geography, Moscow State University, \\ GSP-1, Leninskie Gory 1, 119991 Moscow, Russia \\ E-mail: sokratov@geol.msu.ru
}

\begin{abstract}
We present results from cold-laboratory observations of changes in isotopic $\left(\delta^{18} \mathrm{O}\right.$ and $\left.\delta \mathrm{D}\right)$ content by sublimation in snow and ice samples under nearly isothermal conditions. The results show large increases in observed $\delta^{18} \mathrm{O}$ and $\delta \mathrm{D}$ in snow samples within several centimeters of the surface. They contradict the assumption of a non-changing isotopic content due to layer-by-layer transport mechanisms driven by sublimation/desublimation processes. The data also do not support the idea that isotopic changes of snow and firn are limited by the possibility that the ice matrix incorporates the atmospheric water vapor and that forced water-vapor diffusion in the pore space (wind pumping) is a requirement for isotopic content change. The observations show that sublimation from ice samples results in much lower increases in heavy-isotope content in the first several millimetres near the sublimating surface over the same time period, despite sublimation intensities similar to those of the snow samples. The results suggest that continuous phase transitions inside snow (recrystallization) are the process responsible for the isotopic content change because they are the primary mass-exchange mechanism between the snow mass and the surrounding environment. Modeling the isotopic content of the ice matrix therefore requires inclusion of a two-stage process: fractionation at the ice-matrix surface due to repetitive phase transitions, and fractionation due to preferable diffusion of light water isotopes in the pore space. For interpretation of the observed natural isotopic profiles in snow, the first process can be linked to the time a snow layer undergoes recrystallization, while the second process is related to the total ice/snow mass gain/loss determined by the external environmental conditions.
\end{abstract}

\section{INTRODUCTION}

A fundamental problem in snow science is to quantify mass and energy exchanges at the surface and within the pore space of the snow cover. This information is particularly important for climate-change models since these exchanges influence the global water and energy cycle (Strasser and others, 2008). At present, snow-cover models are based on the assumption that water-vapor sublimation is mainly governed by external forcing (water-vapor flux regulated by temperature gradients within snow cover and mass loss/ gain at the top surface of snow cover regulated by relative humidity, wind speed and radiation). In this paper, we describe the results of experiments devised to find the connection between the mass balance of snow and ice bodies and the evolution of their isotopic content. Previous studies on the isotopic content change of snow (Moser and Stichler, 1975; Sommerfeld and others, 1987, 1991; Friedman and others, 1991; Hachikubo and others, 1997, 2000; Satake and Kawada, 1997) show that the released water vapor has to be lighter in its isotopic content than the remaining bulk ice or liquid water. Thus, measurements of isotopic content are surrogate measures of mass-exchange rates. Therefore, measurements of $\delta^{18} \mathrm{O}$ and $\delta \mathrm{D}$ in natural waters (Shanley and others, 1999; Oeschger, 2000) and snow in particular (Stichler, 1987) can have a wide range of environmental applications.

Isotopic fractionation is associated with the phase transitions at different stages of the water cycle. The water cycle connects evaporation of oceanic water, formation of clouds, cloud transfer by wind far from an initial source of the water vapor, precipitation, and construction of the isotopic content of the run-off back to the ocean (Gat, 1996; Kendall and
Caldwell, 1998; Araguás-Araguás and others, 2000; Taylor and others, 2001). Despite the reported uncertainties in relation to atmospheric circulation patterns, the measured isotopic composition of solid precipitation and variations of the isotopic content in the ground ice and snow are believed to represent climate variations (Moorman and others, 1996; Jouzel and others, 1997; Holdsworth, 2008). The simplest scheme describing these processes was presented by Dansgaard and others (1973, fig. 1). Such schemes are still in use in recent more complex climate reconstructions involving general circulation models (GCMs) (Delaygue and others, 2000; Hoffmann and others, 2000). One of the basic assumptions of such models is that the 'evaporation from solids causes no isotopic fractionation' (Dansgaard and others, 1973, p. 10). In more recent ice-core paleoclimate research this is expressed as: 'the isotopic content of snow $\ldots$ is linearly related to the temperature above the inversion level, ... where precipitation forms, and also to the surface temperature of the precipitation site...', with the two temperatures linearly related as well (Petit and others, 1999, p. 431). In other words, the isotopic content of buried snow represents temperature at the time of deposition.

However, isotopic fractionation does occur in a dry snowpack after deposition, though it is difficult to quantify (Cooper, 1998). Approximate values have been estimated in laboratory experiments (Moser and Stichler, 1975; Sommerfeld and others, 1987, 1991; Hachikubo and others, 2000) and have been reported for natural firn and snow (Friedman and others, 1991; Hachikubo and others, 1997; Satake and Kawada, 1997). Fractionation inside the snow cover is related to the non-equilibrium processes associated with water-vapor diffusion. These processes are considered to explain the isotopic profile homogenization in firn (Johnsen 


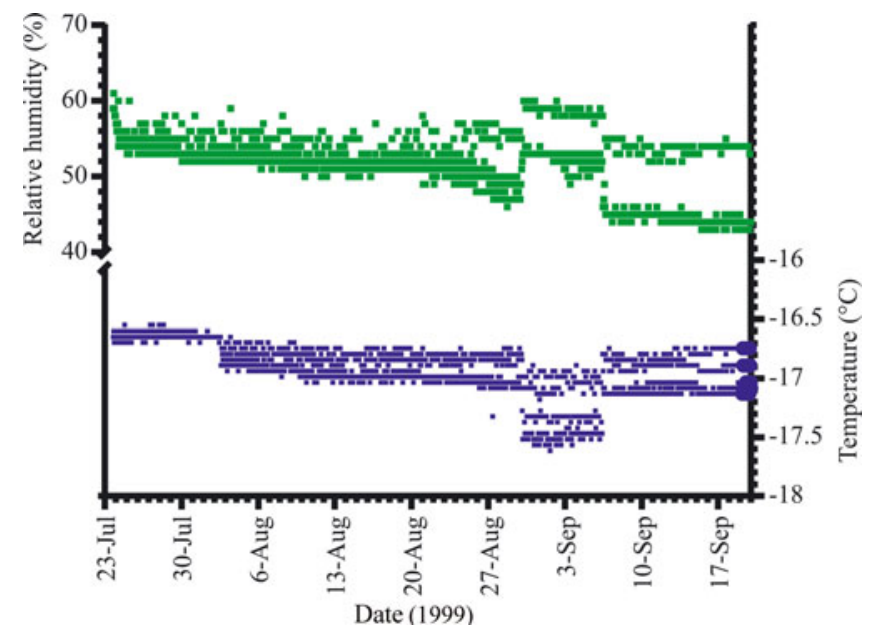

Fig. 1. Measured temperature and relative humidity change during the Shinjo experimental run.

and others, 2000) and lead to the spatial difference in the observed isotopic content of snow and firn caused by mass exchanges between the ice matrix and the atmosphere when enhanced by airflow (Neumann and others, 2005). The fractionation factors involved are taken from experimental observations of the fractionation at an ice surface under controlled equilibrium conditions (e.g. Majoube, 1971).

The results of isotopic content observations in natural snow suggest that isotopic content change also depends on mass exchange with the atmosphere due to sublimation at the snow surface (Hachikubo and others, 1997; Stichler and others, 2001; Konishchev and others, 2003). However, the fact that the observed isotopic content change cannot be explained by mass loss alone requires additional processes to be considered, such as the existence of a liquid layer between the solid ice and the water vapor in the pore space of snow (Sommerfeld and others, 1991).

The question that arises from the current state of knowledge is how the layer-by-layer sublimation, which cannot change the isotopic content of remaining bulk significantly, can coexist with the observed enrichment of sublimating snow cover by heavy stable isotopes. The experiments described below were designed to gather data to answer this question.

\section{EXPERIMENTAL SET-UP}

Two sets of independent experiments were performed in our investigations. The first set was carried out in the cold laboratory of the Shinjo Branch of Snow and Ice Studies, National Institute of Earth Science and Disaster Prevention, Shinjo, Japan, with the artificial snow vapor produced by the Cryospheric Environment Simulator (CES) (http://www. bosai.go.jp/seppyo/jikkentou/jikkentou_syoukai_e.html; Higashiura and others, 1997). The second set was carried out from 11 April 2001 to 22 May 2001 in the cold laboratory of the Laboratory of Snow Avalanches and Debris Flows, Faculty of Geography, Moscow State University, Russia, with natural snow collected in February 2001.

In both cases, in order to minimize disturbance of the environment in the cold room, human activity inside the room was limited to measurements related to these experiments.

\section{Shinjo experiments}

Ten metal Petri dishes (diameter 0.149-0.152 m, height $0.027-0.029 \mathrm{~m}$ ) and two plastic containers (bottom diameter $0.145 \mathrm{~m}$, top diameter $0.15 \mathrm{~m}$, height $0.087 \mathrm{~m}$ ) were used in the experiments. The snow settled for a week in all containers, and before the start of the experiment the excess snow was cut off the top to produce 'fresh' snow at a smooth sublimating surface. Simultaneously, the settled snow produced by the CES was put into plastic bottles which were closed hermetically. One Petri dish was filled with water, the water was frozen, and the ice surface was polished to be at the level of the top edge of the dish.

The samples were positioned on a netted shelf, situated horizontally in the center of a large $(1 \mathrm{~m} \times 1 \mathrm{~m} \times 1 \mathrm{~m})$ plywood box that could be opened from the top. The box was placed in a cold room. All sides of the box were thermoinsulated with hydrophobic foam plastic. A lamp and a fan were installed in one of the bottom corners of the box. An additional fan was placed in a $0.05 \mathrm{~m}$ diameter hole in the wall opposite the lamp. The temperature in the box was regulated by two loggers connected to platinum resistances, one inside and one outside the box. The temperature in the box was set to $-15^{\circ} \mathrm{C}$ while the temperature in the cold room was set to $-20^{\circ} \mathrm{C}$. The accuracy of temperature regulation in the cold room was not better than $\pm 5^{\circ} \mathrm{C}$. The lamp inside the box was automatically switched on or off (with the additional fan in the hole switched off or on) when the temperature inside the box was below or above $-15^{\circ} \mathrm{C}$ respectively. The fan near the lamp was 'on' in either case. All regulation could automatically be switched off if the temperature in the cold room exceeded $-15^{\circ} \mathrm{C}$ (possible during short periods of daily defrosting of the cold room). Such regulation maintained the box at a temperature varying by not more than $\pm 0.3^{\circ} \mathrm{C}$. The temperature difference between the cold room and the inside of the box could cause unplanned condensation of the atmospheric water vapor on the foam plastic walls on the inside of the box, thus drying the incoming air relative to conditions in the cold room. Hourly temperature and humidity inside the box during the experiment were recorded using micro memory loggers.

Every few days the sublimating samples were weighed to an accuracy of $\pm 0.1 \mathrm{~g}$. One closed bottle and one metal cup with snow were removed from the box for isotopic analysis during each weighing. At the final weighing, the snow in the $0.087 \mathrm{~m}$ high containers was taken for isotopic analysis in $0.01-0.015 \mathrm{~m}$ horizontal layers.

During the experiment the amount of snow in the Petri dishes decreased due to sublimation. As a result, the initially smooth sublimating surfaces deformed and, at the end of the experiment, channels formed from the bottom to the top surface in one Petri dish. Snow thickness variations (0.035$0.06 \mathrm{~m}$ ) were observed in the $0.087 \mathrm{~m}$ height cups at the end of the experiment.

Unavoidable temperature variations during the experiment corresponded to the observed variations of air humidity (Fig. 1). A period of notable difference from this general pattern, both in temperature and humidity, was caused by a defective lamp which was exchanged as soon as it was discovered. The decrease in temperature inside the box, with 'normal' temperature conditions outside the box, resulted in an increase in measured relative humidity values. However, we do not rely on the high accuracy of the humidity values reported by the conventional micro memory loggers, partly due to the known problems with 
humidity measurements in cold environments (Makkonen and Laakso, 2005) and partly due to uncertainty in the explanation of the overall relatively steep trend of the measured relative humidity values for a small decrease in air temperature during the described experimental run.

\section{Moscow experiments}

Ice samples were prepared from three types of frozen water: mineralized water, distilled water and melted filtered natural snow. The same snow was used for the sublimation of the 'snow sample'. Glass Petri dishes containing the samples were thermally insulated with thick foam plastic from all sides except the tops, and surrounded by $20 \mathrm{~cm}$ paper walls. The cold-laboratory temperature regulation was controlled by a temperature sensor positioned between the dishes.

Similar to the Shinjo experiments, sublimation resulted in a decrease in sample (especially snow-sample) thickness. Temperature and humidity above the sublimating samples were measured by thermograph and hygrograph and were $-4.3 \pm 1.5^{\circ} \mathrm{C}$ and $78 \pm 10 \%$ respectively.

Isotopic sampling for the analysis was made (1) from initial material and (2) by 'shaving' from the top down in $0.5-1 \mathrm{~mm}$ thick sections (three layers from each sample) at the end of the experiment.

The principal difference in the experimental set-ups was between specifically suppressed air circulation in the Moscow experiments and freely circulating air (though resulting in much higher accuracy in maintaining the temperature regime) in the Shinjo experiments.

\section{EXPERIMENTAL RESULTS AND DISCUSSION}

Intensity of sublimation can be considered as an integrated result of the effect of varying temperature, humidity and airflow velocity on the process of sublimation of snow. The mean intensity of sublimation of the snow and ice samples differed significantly between mass-loss estimations (weightings) during the experimental runs and in the different environmental conditions of the two laboratories (Fig. 2). The ice samples sublimated more intensively than the snow samples in the Shinjo experiments, while the opposite behavior was observed in the Moscow experiments. This difference can be explained by the air circulation conditions in the different cold rooms. Surface roughness can increase the area subjected to sublimation, as shown in the results by the difference in sublimation intensity in the Moscow experiments with stagnant air, and by the increase with time of the ice sublimation intensity in the Shinjo experiments. The latter is likely related to the sublimating erosion of an ice surface, reported by Kuroiwa (1969). Wind velocity is lower over rough snow surfaces than over smooth ice surfaces (Bintanja, 2001). Thus, for the snow samples sublimation intensity should be less affected by wind velocity. The decrease in sublimation intensity of the snow samples may be partly related to wind and sublimation smothering of the snow-sample surfaces relative to their initial state.

The isotopic content of ice samples could only be measured in the Moscow experiments. The fractionation due to solid-to-vapor water phase transition under the conditions and for the time period of the experimental run made the isotopic composition of the remaining bulk heavier by $1-2 \%$ for $\delta^{18} \mathrm{O}$ and by $4-8 \%$ for $\delta \mathrm{D}$. This change was pronounced in 2-3 $\mathrm{mm}$ of ice near a sublimating surface, and

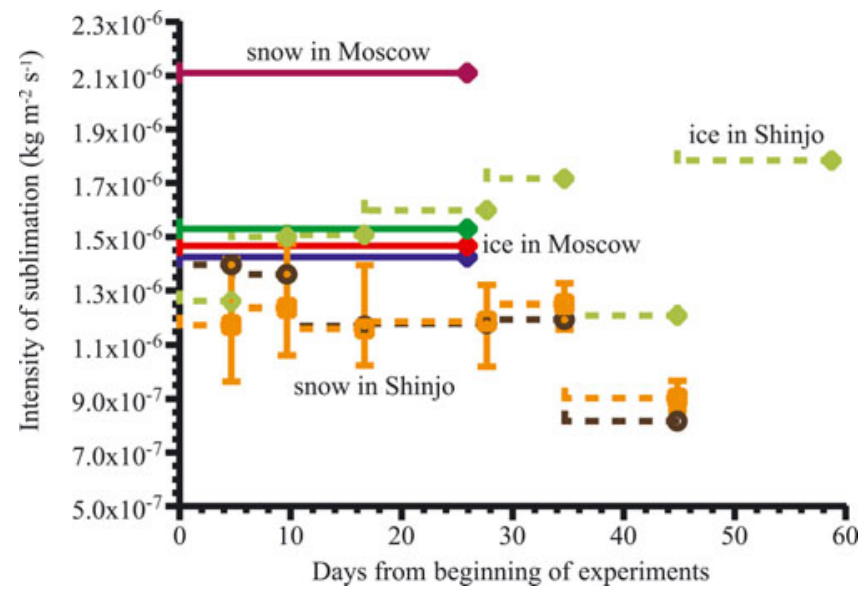

Fig. 2. Intensity of sublimation during both experimental runs. Colors of the solid horizontal bars correspond to the experimental runs as shown in Figure 3 for the experiments in Moscow (three different types of ice samples in Moscow). Dashed bars show the Shinjo results. The length of the horizontal bars indicates the time interval for the mean intensity determination. Vertical bars show the difference between samples where available.

no gradient in heavy-isotope content was clearly identified over this distance (Fig. 3a).

A failure of the refrigerating equipment occurred during the experimental run in Moscow. The samples, hermetically covered by plastic tape, were therefore removed to a colder $\left(-8^{\circ} \mathrm{C}\right)$ refrigerator for 2 days. After refrigeration repair, they were returned to the $-4^{\circ} \mathrm{C}$ cold room where it was found that the internal surface of the plastic tape was covered by sublimate. For some of the ice samples the sublimate was analyzed for its isotopic content. The results show differences in heavy-isotope content between the sublimate and the bulk samples. These are similar to the differences between the initial and final isotopic content of the ice over the whole experimental run (top bars in Fig. 3a). They are attributed to more active condensation of heavy isotopes at the tape from the water vapor produced by sublimation from warmer ice after temporary positioning in the refrigerator.

The isotopic content change in snow samples at the end of the experimental run was much greater than that observed in ice samples, about $8 \%$ for $\delta^{18} \mathrm{O}$ and about $40 \%$ for $\delta \mathrm{D}$. There was a pronounced gradient in heavy-isotope content near the sublimating snow-sample surface (Fig. 3b).

In the Shinjo experiments the 'initial' isotopic composition of the snow samples was measured in snow kept in sealed plastic bottles during the experimental run. Observation of eight such samples yields $\delta^{18} \mathrm{O}=-7.3 \pm 0.1 \%$, which confirms the uniformity of the initial isotopic content of the sublimating snow. The isotopic content of the tap water was not measured, but was expected to be $\delta^{18} \mathrm{O} \approx$ $-9 \%$ and $\delta \mathrm{D} \approx-60 \%$. The initial $\delta$ values of snow were higher as a result of fractionation during snow-grain formation $\left(\delta^{18} \mathrm{O}=-7.3 \%, \delta \mathrm{D}=-46 \%\right.$ ), and close to the previously measured values of the snow produced in the CES $\left(\delta^{18} \mathrm{O} / \delta \mathrm{D}\right.$ were $-7.3 /-42$ and $-7.6 /-43$ respectively).

However, in the Moscow experiments, continuous change in the isotopic content of the sublimating snow was observed (Fig. 4a). The change shows nearly linear dependence on mass loss, which, except for the range of $\delta$ values, in general corresponds to previously reported results (Moser and Stichler, 1975, 1980), and presents heavy-isotope enrichment 
a

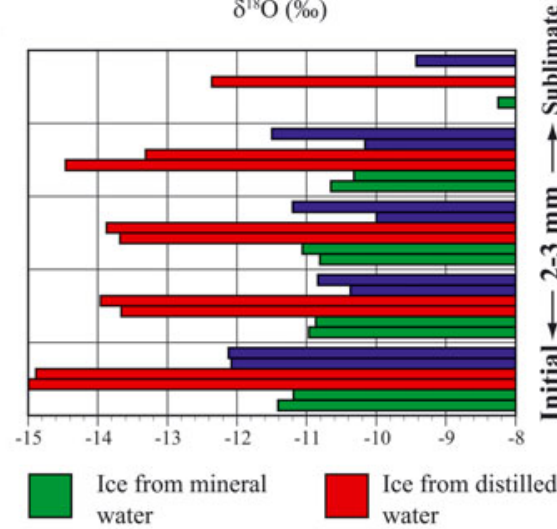

b

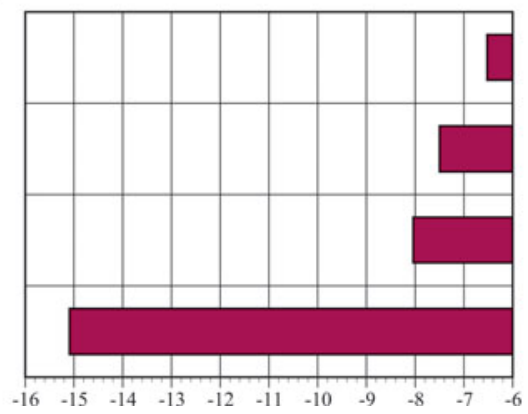

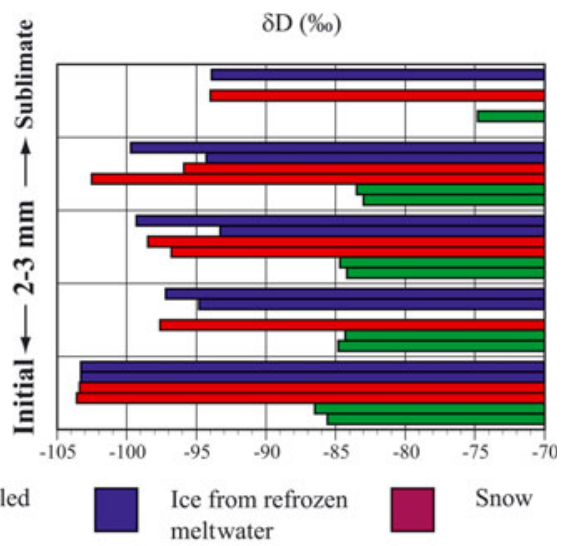

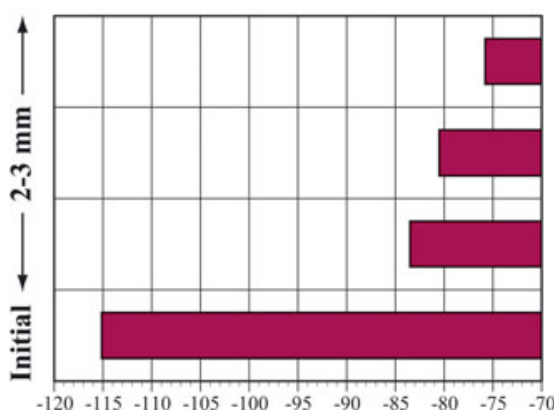

Fig. 3. Isotopic content measured in (a) ice and (b) snow samples in Moscow experiments. The layers from top down correspond to sublimate (for ice only), three 'shaved' layers (2-3 mm thick in total) and the original bulk material.

of $5 \%$ for $\delta^{18} \mathrm{O}$ and $\sim 20 \%$ for $\delta \mathrm{D}$. For the final stage, vertical profiles of $\delta^{18} \mathrm{O}$ and $\delta \mathrm{D}$ over the remaining snow-sample thickness in the $0.087 \mathrm{~m}$ high containers were obtained (Fig. 4b). Extrapolation of the observed $\delta^{18} \mathrm{O}$ profile suggested the isotopic content in the immediate vicinity of the sublimating surface was similar to the final measurements in the time series with the Petri dishes (Fig. 4a). The same probably applies to the $\delta \mathrm{D}$ values; unfortunately, however, few $\delta \mathrm{D}$ measurements were possible. The available values constructing the $\delta^{18} \mathrm{O} / \delta \mathrm{D}$ dependence are shown in Figure 5.

As a result of sublimation from the snow samples, the isotopic content of the remaining snow became noticeably heavier and the departure from the global meteoric waterline (Fig. 5) corresponds to those explained by evaporation from an open surface (Clark and Fritz, 1997).

\section{CONCLUSIONS AND APPLICATIONS}

Our experimental results are in agreement with previous data on isotopic content change in snow, suggesting that the lost material (water vapor) was lighter in isotopic content than the remaining bulk. This is due to the dependence of the diffusion coefficients of isotopic molecules of water on the molecular mass.
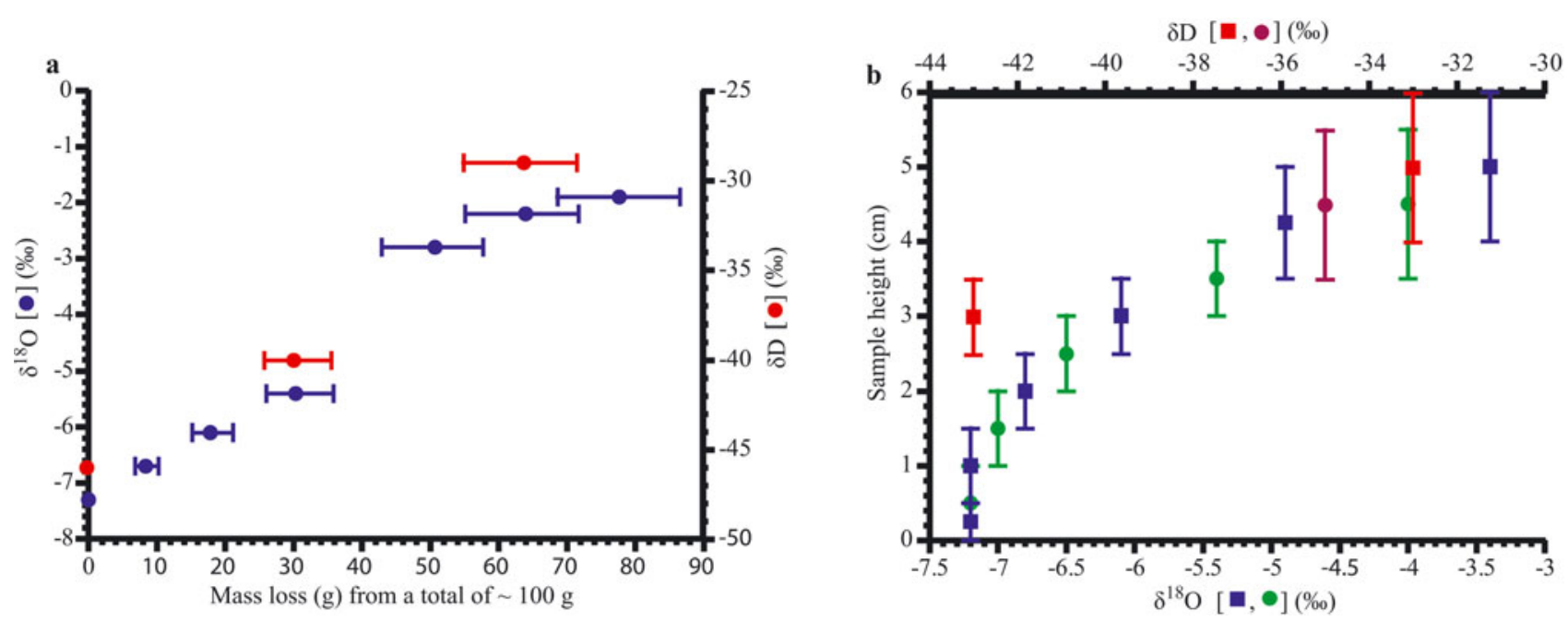

Fig. 4. Isotopic content of snow samples in Shinjo experiments: (a) changing with mass loss (near-linear with time) in samples from metal cups (horizontal bars show the possible error in mass loss determination); and (b) at the end of the experiment for 'thick' samples (vertical bars show the thickness of layers taken for analysis). 
The presented results suggest the following interplay between the theoretically expected layer-by-layer sublimation/desublimation at the ice-matrix surface and the isotopic content evolution of snow cover due to mass exchange between the snow cover and the atmosphere:

The process of sublimation is continuous molecular exchange between the phases at the interface, with only part of the released water vapor transferred out of the system when conditions allow. The empirical equilibrium fractionation factors corresponding to this mass exchange are not directly linked to the overall evolution of the isotopic content of snow. The latter is affected at least by the specific surface area of snow exposed to mass exchange (Horita and others, 2008) and by the depth of the snow layer exposed to the mass exchange with the atmosphere (He and Smith, 1999). Several centimeters of snow are a source of sublimation from snow, partly because of interconnection of pores and partly due to observed sublimative cooling resulting in temperature gradient formation (Golubev and Sokratov, 1991). This is supported by our experimental results (Fig. 4b).

In principle, the process of isotopic content change by sublimation can be linked to the model approach of Feng and others (2002), which has been shown to describe the isotopic content change of snow due to repetitive melting/refreezing (Zhou and others, 2008). However, modeling of the fractionation due to sublimation requires an accurate enough description of the dependence of the activity of recrystallization of snow on environmental parameters (Sokratov, 2001; Bartelt and others, 2004). The data provided by computed micro-tomography (Schneebeli and Sokratov, 2004) show that the mass exchange between the neighboring ice-matrix structures (recrystallization of snow) can be orders of magnitude higher than the mass transferred in the direction of a temperature gradient due to water-vapor concentration variation (Sokratov and others, 2004).

For application to natural snow covers, the experimental results suggest that the isotopic content, in addition to the initial isotopic content of solid precipitations and activity of sublimation, is regulated by the time of exposure of deposited snow to the atmosphere (Moser and Stichler, 1975). The latter depends on the time between precipitation events and their amount of precipitation. A snow-cover depth dependence of evolution of the isotopic content has been reported for northern Eurasia (Konishchev and others, 2003).

Since the isotopic content of snow is determined by the 'openness' of the system, similar effects must be expected in glacier snow and firn down to considerable depths. Though the mass fluxes deep below the surface are small, the duration of the ice-matrix surface exposure to fractionation during gradual sinkage of each specific snow layer (due to accumulation at the surface) reaches tens or hundreds of years.

In addition to the dependence on temperature at the moment of deposition (linear, according to Petit and others (1999)), the isotopic content in a buried snow layer is determined by (1) relative mass loss during the layer presence near the day surface (the surface exposed to light), (2) dependence of snow recrystallization activity on the snow layer temperature (presumably exponential, when determined by the water-vapor content in the pore space of snow), varying seasonally and in the long term, and (3) possible changes in the mass transfer into and out of the layer, varying with the depth and age of the snow layer. Despite a considerable literature on the isotopic composition of snow, estimation of

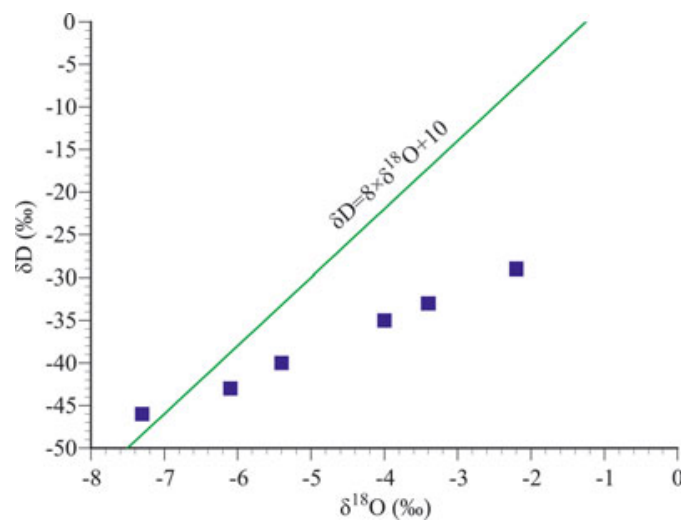

Fig. 5. The $\delta^{18} \mathrm{O} / \delta \mathrm{D}$ ratio for snow samples in the experimental run at Shinjo.

the importance of the above listed processes in various applications still requires additional experimental data on simultaneously measured isotopic content change and environmental parameters responsible for fractionation due to sublimation.

\section{ACKNOWLEDGEMENTS}

The research was supported by the Joint Russian Foundation of Basic Research (RFBR) and National Natural Science Foundation, China, grant No. 05-05-39011-GFEN and RFBR grant No. 08-05-00874_a. Some of the reported experimental data (Shinjo experimental run) were obtained with the support of a research grant from Science and Technology Agency of Japan. We thank O. Matsubaya (Akita University, Akita, Japan) and $\mathrm{H}$. Meyer (stable isotope laboratory of the Alfred Wegener Institute for Polar and Marine Research, Germany) for isotopic analysis of the Shinjo and Moscow experimental samples respectively. We are grateful to the scientific editor P. Bartelt who provided assistance 'beyond the call of duty' and without which this paper would not have been published. Suggestions for improving the paper, by $\mathrm{E}$. Adams and several anonymous reviewers over the last 5 years, are very much appreciated.

\section{REFERENCES}

Araguás-Araguás, L., K. Froelich and K. Rozanski. 2000. Deuterium and oxygen-18 isotope composition of precipitation and atmospheric moisture. Hydrol. Process., 14(8), 1341-1355.

Bartelt, P., O. Buser and S. Sokratov. 2004. A nonequilibrium treatment of heat and mass transfer in alpine snowcovers. Cold Reg. Sci. Technol., 39(2-3), 219-242.

Bintanja, R. 2001. Characteristics of snowdrift over a bare ice surface in Antarctica. J. Geophys. Res., 106(D9), 9653-9659.

Clark, I.D. and P. Fritz. 1997. Environmental isotopes in hydrogeology. Boca Raton, FL, CRC Lewis.

Cooper, L.W. 1998. Isotopic fractionation in snow cover. In Kendall, C. and J.J. McDonnell, eds. Isotope tracers in catchment hydrology. New York, Elsevier, 119-136.

Dansgaard, W., S.J. Johnsen, H.B. Clausen and N. Gundestrup. 1973. Stable isotope glaciology. Medd. Grønl., 197(2), 1-53.

Delaygue, G., J. Jouzel, V. Masson, R.D. Koster and E. Bard. 2000. Validity of the isotopic thermometer in central Antarctica: limited impact of glacial precipitation seasonality and moisture origin. Geophys. Res. Lett., 27(17), 2677-2680.

Feng, X., S. Taylor, C.E. Renshaw and J.W. Kirchner. 2002. Isotopic evolution of snowmelt 1. A physically based one-dimensional 
model. Water Resour. Res., 38(10), 1217. (10.1029/ 2001WR000814.)

Friedman, I., C. Benson and J. Gleason. 1991. Isotopic changes during snow metamorphism. In Taylor, H.P., Jr, J.R. O'Neill and I.R. Kaplan, eds. Stable isotope geochemistry: a tribute to Samuel Epstein. Washington, DC, Geochemical Society, 211-221. (Special Publication 3.)

Gat, J.R. 1996. Oxygen and hydrogen isotopes in the hydrologic cycle. Annu. Rev. Earth Planet. Sci., 24, 225-262.

Golubev, V.N. and S.A. Sokratov. 1991. Isparenie snega v izotermicheskikh usloviiakh [Evaporation of snow under isothermal conditions]. Mater. Glyatsiol. Issled. 71, 27-32. [In Russian with English summary.]

Hachikubo, A., H. Motoyama, K. Suzuki and E. Akitaya. 1997. Fluctuation of $\delta^{18} \mathrm{O}$ of surface snow with surface hoar and depth hoar formation under radiative cooling. Proc. NIPR Symp. Polar Meteorol. Glaciol., 11, 94-102.

Hachikubo, A., S. Hashimoto, M. Nakawo and K. Nishimura. 2000. Isotopic mass fractionation of snow due to depth hoar formation. Polar Meteorol. Glaciol., 14, 1-7.

He, H. and R.B. Smith. 1999. An advective-diffusive isotopic evaporation-condensation model. J. Geophys. Res., 104(D15), $18,619-18,630$

Higashiura, M. and 6 others. 1997. Preparation of the experimental building for snow and ice disaster prevention. In Izumi, M., T. Nakamura and R.L. Sack, eds. Snow engineering: recent advances. Rotterdam, A.A. Balkema, 605-608.

Hoffmann, G., J. Jouzel and V. Masson. 2000. Stable water isotopes in atmospheric general circulation models. Hydrol. Process., 14(8), 1385-1406.

Holdsworth, G. 2008. A composite isotopic thermometer for snow. J. Geophys. Res., 113(D8), D08102. (10.1029/2007JD008634.)

Horita, J., K. Rozanski and S. Cohen. 2008. Isotope effects in the evaporation of water: a status report of the Craig-Gordon model. Isot. Environ. Health Stud., 44(1), 23-49.

Johnsen, S.J., H.B. Clausen, K.M. Cuffey, G. Hoffmann, J. Schwander and T. Creyts. 2000. Diffusion of stable isotopes in polar firn and ice: the isotope effect in firn diffusion. In Hondoh, T., ed. Physics of ice core records. Sapporo, Hokkaido University Press, 121-140.

Jouzel, J. and 12 others. 1997. Validity of the temperature reconstruction from water isotopes in ice cores. J. Geophys. Res., 102(C12), 26,471-26,487.

Kendall, C. and E.A. Caldwell. 1998. Fundamentals of isotope geochemistry. In Kendall, C. and J.J. McDonnell, eds. Isotope tracers in catchment hydrology. New York, Elsevier, 51-86.

Konishchev, V.N., V.N. Golubev and S.A. Sokratov. 2003. Sublimation from a seasonal snow cover and an isotopic content of ice wedges in the light of a paleoclimate reconstruction. In Philips, M., S.M. Springman and L.U. Arenson, eds. Permafrost: Proceedings of the Eighth International Conference on Permafrost, 21-25 July 2003, Zürich, Switzerland, Vol. 1. Lisse, Swets \& Zeitlinger, 585-590.

Kuroiwa, D. 1969. Surface topography of etched ice crystals observed by a scanning electron microscope. J. Glaciol., 8(54), 475-483.

Majoube, M. 1971. Fractionnement en oxygène-18 entre la glace et la vapeur d'eau. J. Chim. Phys., 68(4), 625-636.

Makkonen, L. and T. Laakso. 2005. Humidity measurements in cold and humid environments. Bound.-Layer Meteorol., 116(1), 131-147.

Moorman, B.J., F.A. Michel and R.J. Drimmie. 1996. Isotopic variability in Arctic precipitation as a climatic indicator. Geosci. Canada, 23(4), 189-194.
Moser, H. and W. Stichler. 1975. Deuterium and oxygen-18 contents as an index of the properties of snow covers. IAHS Publ. 114 (Symposium at Grindelwald 1974 - Snow Mechanics), 122-135.

Moser, H. and W. Stichler. 1980. Environmental isotopes in ice and snow. In Fritz, P. and J.C. Fonte, eds. Handbook of environmental isotope geochemistry. Amsterdam, Elsevier Publishing Co., 141-178.

Neumann, T.A., E.D. Waddington, E.J. Steig and P.M. Grootes. 2005. Non-climate influences on stable isotopes at the Taylor Mouth, Antarctica. J. Glaciol., 51(173), 248-258.

Oeschger, H. 2000. Perspectives on global change science: isotopes in the Earth system, past and present. Quat. Sci. Rev., 19(1-5), 37-44.

Petit, J.R. and 18 others. 1999. Climate and atmospheric history of the past 420,000 years from the Vostok ice core, Antarctica. Nature, 399(6735), 429-436.

Satake, H. and K. Kawada. 1997. The quantitative evaluation of sublimation and the estimation of original hydrogen and oxygen isotope ratios of a firn core at East Queen Maud Land, Antarctica. Bull. Glacier Res., 15, 93-97.

Schneebeli, M. and S.A. Sokratov. 2004. Tomography of temperature gradient metamorphism of snow and associated changes in heat conductivity. Hydrol. Process., 18(18), 3655-3665.

Shanley, J.B. and 25 others. 1999. Isotopes as indicators of environmental change. In Kendall, C. and J.J. McDonnell, eds. Isotope tracers in catchment hydrology. Amsterdam, Elsevier.

Sokratov, S. 2001. Parameters influencing the recrystallization rate of snow. Cold Reg. Sci. Technol., 33(2-3), 263-274.

Sokratov, S.A., T.U. Kaempfer and M. Schneebeli. 2004. Temperature gradient metamorphism observed by computed microtomography. In Hellström, R. and S. Frankenstein, eds. Proceedings of the 61st Eastern Snow Conference, 9-11 June 2004, Portland, Maine, USA. Hanover, NH, US Army Cold Regions Research and Engineering Laboratory, 55-58.

Sommerfeld, R.A., I. Friedman and M. Nilles. 1987. The fractionation of natural isotopes during temperature gradient metamorphism of snow. In Jones, H.G. and W.J. Orville-Thomas, eds. Seasonal snowcovers: physics, chemistry, hydrology. Dordrecht, etc., D. Reidel Publishing Co., 95-105. (NATO ASI Series C: Mathematical and Physical Sciences 211.)

Sommerfeld, R.A., C. Judy and I. Friedman. 1991. Isotopic changes during the formation of depth hoar in experimental snowpacks. In Taylor, H.P., Jr, J.R. O'Neill and I.R. Kaplan, eds. Stable isotope geochemistry: a tribute to Samuel Epstein. Washington, DC, Geochemical Society, 205-209. (Special Publication 3.)

Stichler, W. 1987. Snowcover and snowmelt processes studied by means of environmental isotopes. In Jones, H.G. and W.J. OrvilleThomas, eds. Seasonal snowcovers: physics, chemistry, hydrology. Dordrecht, etc., D. Reidel Publishing Co., 673-726. (NATO ASI Series C: Mathematical and Physical Sciences 211.)

Stichler, W., U. Schotterer, K. Fröhlich, P. Ginot, C. Kull and H.W. Gäggeler. 2001. The influence of sublimation on stable isotope records recovered from high altitude glaciers in the tropical Andes. J. Geophys. Res., 106(D19), 22,613-22,620.

Strasser, U., M. Bernhardt, M. Weber, G.E. Liston and W. Mauser. 2008. Is snow sublimation important in the alpine water balance? Cryosphere, 2(1), 53-66.

Taylor, S., X. Feng, J.W. Kirchner, R. Osterhuber, B. Klaue and C.C. Renshaw. 2001. Isotopic evolution of a seasonal snowpack and its melt. Water Resour. Res., 37(3), 759-769.

Zhou, S., M. Nakawo, S. Hashimoto and A. Sakai. 2008. The effect of refreezing on the isotopic composition of melting snowpack. Hydrol. Process., 22(6), 873-882. 